\title{
Single-Dose Pharmacokinetics of HLD200, a Delayed- Release and Extended-Release Methylphenidate Formulation, in Healthy Adults and in Adolescents and Children with Attention-Deficit/Hyperactivity Disorder
}

\author{
Ann Childress, MD, Shailly Mehrotra, BPharm,2 Jogarao Gobburu, PhD, MBA, \\ Angus McLean, $\mathrm{PhD}^{3}$, Norberto J. DeSousa, $\mathrm{MA}^{3}$, and Bev Incledon, $\mathrm{PhD}^{3}$
}

\begin{abstract}
Objective: Current extended-release (ER) formulations of psychostimulants used for treatment of attention-deficit/ hyperactivity disorder (ADHD) provide an extended duration of ADHD symptom control; however, the onset of efficacy can be protracted and variable, leaving the early morning untreated. The primary objective was to characterize the single-dose pharmacokinetics and tolerability of HLD200, an evening-dosed, delayed-release (DR) and ER formulation of methylphenidate (MPH), in healthy adults and in adolescents and children with ADHD.

Methods: The pharmacokinetics and tolerability of a single, oral evening dose of HLD200 (54 mg) were evaluated in two single-center open-label studies: the first in healthy adults $(n=12)$ and the second in adolescents $(n=18)$ and children $(n=11)$ with ADHD. Primary pharmacokinetic endpoints were the rate and extent of $\mathrm{MPH}$ absorption $\left(\mathrm{C}_{\max }\right.$ and area under the curve [AUC]) and time to peak concentration $\left(\mathrm{T}_{\max }\right)$. These parameters were calculated using noncompartmental analysis.

Results: HLD200 produced a pharmacokinetic profile characterized by an 8- to 10-hour delay in MPH release, followed by a period of extended controlled release, resulting in an ascending absorption profile that coincided with the early morning and afternoon. Mean values (coefficient of variation $[\mathrm{CV}] \%$ ) of weight-adjusted pharmacokinetic parameters were similar in adults and in adolescents and children with ADHD: $\mathrm{C}_{\max }([\mathrm{ng} / \mathrm{mL}] /[\mathrm{mg} / \mathrm{kg}])$ was 9.1 (35.2), 8.8 (34.5), and 7.4 (30.1); $\mathrm{AUC}_{0-\mathrm{t}}$ $([\mathrm{ng} \cdot \mathrm{h} / \mathrm{mL}] /[\mathrm{mg} / \mathrm{kg}])$ was $126.5(35.5), 129.4(34.8)$, and $129.7(27.3)$; and $\mathrm{T}_{\max }$ (hours) was 15.6(11.1), 17.1 (14.5), and 17.7 (14.1), respectively. Intersubject variability in the mean time to achieve ascending plasma MPH concentrations of 2, 3, 4, and $5 \mathrm{ng} / \mathrm{mL}$ was low (CV: $7.8 \%-17.7 \%)$.

Conclusions: Evening-dosed HLD200 produces the intended DR and ER pharmacokinetic profile that provides a consistent predictable delay in initial MPH release until the early morning, followed by extended release across the day. The body weight-adjusted pharmacokinetics of HLD200 were similar between adults and adolescents and children with ADHD.
\end{abstract}

Keywords: methylphenidate, attention-deficit/hyperactivity disorder, pharmacokinetics, delayed-release, extended-release

\section{Introduction}

A TTENTION-DEFICIT/HYPERACTIVITY DISORDER (ADHD) is the most commonly diagnosed and treated childhood-onset neurobehavioral disorder, with an estimated prevalence of $5.9 \%-7.1 \%$ in children and adolescents (Willcutt 2012). Children with ADHD may have the disorder persist into adulthood in $\sim 50 \%-70 \%$ of cases (McGough and Barkley 2004; Wilens and Spencer 2010). Psychostimulants, methylphenidate (MPH) and amphetamine, have been used to treat ADHD for over 60 years and are currently recommended as first-line pharmacotherapy for children and adolescents with ADHD (Pliszka and AACAP Work Group on Quality Issues 2007; Subcommittee on Attention-Deficit/Hyperactivity Disorder and Steering et al. 2011; Childress 2016). Of these, MPH

\footnotetext{
${ }^{1}$ The Center for Psychiatry and Behavioral Medicine, Las Vegas, Nevada.

${ }^{2}$ Center for Translational Medicine, School of Pharmacy, University of Maryland, Baltimore, Maryland.

${ }^{3}$ Ironshore Pharmaceuticals and Development, Inc., Grand Cayman, Cayman Islands.

These studies were presented as an abstract at the American Professional Society of ADHD and Related Disorders Annual Meeting, Washington, DC, January 13-15, 2017.

Funding: Ironshore Pharmaceuticals and Development, Inc. funded this study.
}

(c) Ann Childress et al. 2017; Published by Mary Ann Liebert, Inc. This is an Open Access article distributed under the terms of the Creative Commons Attribution License, which permits unrestricted use, distribution, and reproduction in any medium, provided the original work is properly cited. 
has been the stimulant of choice in children (Volkow et al. 2002; Childress 2016). MPH inhibits the reuptake of dopamine and norepinephrine into the presynaptic neuron by blocking their respective reuptake transporters, and the resulting increase in these neurotransmitters is considered the basis for its clinical efficacy (Swanson et al. 1999; Volkow et al. 2002).

Immediate-release (IR) MPH (Ritalin ${ }^{\circledR}$ ) was the first MPHbased pharmacotherapy approved by the Food and Drug Administration (FDA) for the treatment of ADHD (Maldonado 2013; Childress 2016). However, the therapeutic effects of IR MPH wear off within 3-4 hours, requiring twice- or thrice-daily dosing to achieve symptom control (Swanson et al. 2003). This presents a number of significant challenges, including fluctuating peak and trough drug plasma concentrations that may increase the risk of adverse events (AEs) or result in a potential loss of efficacy; the inconvenience of school day administration, which may result in embarrassment, stigma, and lack of privacy for the patient; reduced treatment compliance; and the potential for diversion (Swanson et al. 1999; López and Leroux 2013; Maldonado 2013).

In light of these challenges, sustained-release (SR) formulations of MPH were initially developed, but they were not as effective as IR formulations and not widely accepted in clinical practice (Pelham et al. 1987; Swanson et al. 1999, 2003). The reduced efficacy of SR formulations was attributed to acute tolerance resulting from the flat (zero-order) drug delivery profile, and accordingly, an ascending (first-order) drug delivery profile was proposed to overcome or minimize this tachyphylaxis (Birmaher et al. 1989; Hubbard et al. 1989; Swanson et al. 1999, 2003).

Consequently, several extended-release (ER) formulations of MPH have since been developed to mimic twice- or thrice-daily administration of IR MPH. Almost all ER formulations exhibit biphasic absorption characteristics by combining an initial rapid release of MPH, followed by a subsequent prolonged phase of drug delivery (Swanson et al. 2003; López and Leroux 2013; Maldonado 2013). The drug release profiles of these ER formulations vary depending on the type of drug delivery system used and ratios of IR to ER MPH, giving each formulation a unique pharmacokinetic profile, which is reflected in their pharmacodynamic properties, including onset, magnitude, and duration of effect (López and Leroux 2013; Maldonado 2013). Additionally, variations in gastrointestinal (GI) transit and $\mathrm{pH}$ can also alter the bioavailability and absorption of MPH released from oral ER formulations (López and Leroux 2013).

Currently available ER MPH formulations are given once daily in the morning to provide control of ADHD symptoms for a period of up to 12 hours after dosing; however, they can have a delay in the initial onset of action of up to 2 hours (Childress 2016; Childress and Tran 2016). This leaves the critical early morning routinespanning the temporal period between awakening and before the school day or other morning activities begin-without adequate ADHD symptom management (Whalen et al. 2006; Sallee 2015). Two recent quantitative research surveys of primary caregivers, whose children and adolescents with ADHD were taking stable doses of commonly prescribed stimulant medications (primarily ER formulations), have highlighted a significant unmet need in providing clinically meaningful control of early morning ADHD symptoms and impairment of early morning functioning (EMF) (Sallee 2015; Faraone et al. 2017). Specifically, in both surveys, $91 \%$ of the surveyed caregivers reported that inadequately controlled ADHD symptoms manifested with at least mild severity in their children with ADHD during the early morning routine. Of these, more than $75 \%$ of caregivers regarded the early morning routine as a time frequently associated with moderate-to-severe
ADHD symptoms and related functional impairments in their children and adolescents despite routine morning administration of their primary stimulant medications. In fact, almost half of the surveyed parents reported that this problem is so acute that they awoke before their child's normal wakening time to administer ADHD medication in an attempt to help mitigate early morning ADHD symptoms, such as being easily distracted, not listening, and the inability to focus on tasks (Sallee 2015; Faraone et al. 2017). This approach could potentially exacerbate challenges in the afternoon and evening periods for these patients.

A novel approach to providing early morning ADHD symptom control and a reduction in EMF impairment involves utilizing a formulation technology that facilitates evening administration of medication and release of the psychostimulant just before awakening. This approach, however, would have to provide an initial extended delay in stimulant release, be precise in the timing of that release, and hinder any inadvertent release of stimulant during the sleep cycle. A decided advantage of such an approach would be little to no downtime in symptom coverage during the morning period because plasma MPH levels would have already started to ascend just before the child's normal awakening time. The formulation also needs to build upon the knowledge of Swanson et al. (1999), who initially proposed the superiority of MPH dosing regimens that produce an ascending plasma concentration profile. However, a major challenge that currently available ER MPH formulations have not been able to overcome has been to both initiate and sustain the absorption phase to attain both the onset and duration of clinically meaningful effects from the early morning and throughout the late afternoon and early evening.

HLD200 is a new, oral, once-daily, delayed-release (DR) and ER formulation of MPH (DR/ER-MPH) that utilizes the proprietary DELEXIS $^{\circledR}$ drug delivery platform. DELEXIS was specifically engineered to provide a consistent delay in the initial release of MPH after ingestion, followed by a period of extended controlled release. The platform utilizes a sophisticated microbead technology comprising two functional film coatings surrounding an MPH-loaded core. The outer DR layer comprises hydrophobic, hygroscopic, and $\mathrm{pH}$-dependent polymers designed to provide a prolonged predictable delay in drug release to target the therapeutic effect upon awakening. The inner ER layer comprises hydrophobic and soluble polymers designed to regulate permeability and tightly control the dissolution of MPH, which enables prolonged absorption in the colon. This is intended to provide an extended drug release to control symptoms and improve functional impairments throughout the day and into the evening. Based on the properties of the DR and ER layers, the initial dissolution and subsequent absorption of MPH are not dependent on any single factor, such as a $\mathrm{pH}$ trigger, normal variations in GI transit, or site of release, thereby minimizing inter- and intrapatient variability.

The feasibility of HLD200 to safely and precisely control the release and absorption of MPH following evening dosing was evaluated in two single-center open-label studies. The objectives of these studies were to (1) characterize the single-dose pharmacokinetics and tolerability of HLD200 in healthy adults and in adolescents and children with ADHD and (2) compare the pharmacokinetics of HLD200 in these three populations.

\section{Methods}

\section{Study conduct}

The pharmacokinetics and tolerability of a single oral evening dose of HLD200 were evaluated in two studies. The first study 
(Study I) was a phase I, single-center, single-dose, open-label, randomized, crossover, comparative bioavailability trial comparing two formulations of HLD200 in healthy adult volunteers. The second study (Study II) was a phase I/II, single-center open-label trial (NCT01907360) evaluating a single dose of HLD200 after evening oral administration in adolescents and children with ADHD. Both studies were conducted at separate sites by different investigators in accordance with the Declaration of Helsinki, Good Clinical Practice guidelines of the International Conference on Harmonization, and all applicable local/country-specific laws and regulations. All participants and parents/legal guardians provided written documentation of informed consent/assent and consent, respectively, under procedures approved by the Institutional Review Board.

\section{Participants}

Study I. Twelve healthy adult volunteers (six males and six females) between 18 and 55 years of age were enrolled. Participants were considered eligible for inclusion in the study if they were in general good health with no significantly abnormal findings during a physical examination, had no clinically significant abnormal laboratory or electrocardiogram (ECG) findings, and had a body mass index of $20-30 \mathrm{mg} / \mathrm{kg}^{2}$. Female participants were required to have a negative urine pregnancy test result and those of childbearing potential were required to practice effective contraception during the study and be willing to continue contraception for a month after their last dose of the study treatment.

Participants were not permitted to enroll if any of the following exclusion criteria were met: (1) history or presence of clinically significant cardiovascular, pulmonary, hepatic, renal, hematologic, GI, endocrine, immunologic, dermatologic, neurologic, oncologic, or psychiatric disease; (2) history of glaucoma; (3) history of psychiatric conditions of clinical significance, such as mood disorders (e.g., depression, schizophrenia), anxiety, ADHD, seizures (except febrile seizures as a child), motor tics, or current diagnosis or family history of Tourette's syndrome; (4) history of illicit or prescription drug abuse or alcohol abuse in the past year or current evidence of such abuse or addition (e.g., positive urine drug and/or alcohol screen); (5) history of any condition that would place the participant at risk of AEs, may compromise study assessments, or may interfere with the absorption, distribution, metabolism, or excretion of the study drug; (6) positive for human immunodeficiency virus (HIV), hepatitis B, or hepatitis C; and (7) pregnant or lactating. Participants were also excluded if they had a clinically significant acute illness 7 days before Clinical Research Unit (CRU) admission; donated plasma within 7 days or one or more pints of blood (or equivalent blood loss) within 30 days before CRU admission; an allergy to the active or inactive components of HLD200; or participated in a clinical trial with an investigational drug within 30 days or five half-lives of the medication before CRU admission.

All participants were required to abstain or refrain from (1) consuming any herbal medications or supplements, prescription drugs (except contraceptives), antacids, or grapefruit products 14 days before CRU admission until the end of the study; (2) consuming any alcohol, xanthine- or caffeine-containing products, dietary supplements, nonprescription drugs, or poppy-containing products 3 days before CRU admission until the end of the study; (3) smoking during the inpatient period of the study; and (4) any strenuous physical activity.

Study II. Eighteen adolescents (13-17 years) and 11 children (612 years) previously diagnosed with ADHD were enrolled. The Mini
International Neuropsychiatric Interview for Children and Adolescents was used to confirm ADHD. At the time of enrollment, all participants were either on a stable dose of MPH or known to have a previous history of symptom control on MPH. Participants had to be deemed free of clinically significant findings, as determined by a physical examination. Additionally, all participants had to be able to swallow the treatment capsules, able to tolerate venipuncture, and available for the entire study period. Female participants of childbearing potential were required to have a negative urine pregnancy test result and were given specific instructions on how to avoid pregnancy during the trial.

Participants were not permitted to enroll if any of the following exclusion criteria were met: (1) history or presence of clinically significant cardiovascular, pulmonary, hepatic, renal, hematologic, GI, endocrine, immunologic, dermatologic, neurologic, and ophthalmologic disease; (2) presence of any significant physical or organ abnormality; (3) any clinically significant illness 4 weeks before the study; (4) severe comorbid psychiatric diagnosis that may affect safety or compromise study assessments; (5) current suicidal ideation or history of suicidality, as determined by the Columbia-Suicide Severity Rating Scale (C-SSRS); (6) positive screening for illicit drug use and/or use of medications that may affect safety or compromise study assessments; (7) known history of moderate-to-severe asthma, severe allergic reactions, seizures (except febrile seizures before 5 years of age), anorexia nervosa, bulimia, or current diagnosis or family history of Tourette's disorder; (8) positive history for hepatitis B, hepatitis C, and HIV; or (9) severely underweight or overweight (at the discretion of the investigation). In addition, participants were excluded if they had participated in a clinical trial with an investigational drug within 30 days preceding study enrollment; had taken any prescription medications (except ADHD medications) within 7 days or over-the-counter medications (except contraceptives) within 3 days preceding study enrollment, unless deemed acceptable by the investigator and clinical/medical monitor; or underwent blood draws of 50-249, 250-449, and $\geq 450 \mathrm{~mL}$ within 30 , 45 , and 60 days preceding study enrollment, respectively.

\section{Study design, treatment, and procedures}

Study I. The adult study was conducted between April and May 2013 in a three-way crossover Latin Square design with three sequences that involved the comparison of two 54-mg HLD200 formulations, a slow-release formulation (MPH00400) and a fastrelease formulation (MPH00500) with IR MPH (Ritalin $20 \mathrm{mg}$ ) as the reference formulation. Participants $(n=12)$ were organized into three cohorts with each cohort comprising four participants, and all participants received each of the three treatments in a randomized, crossover complete Latin Square design. The two HLD200 formulations were administered at $\sim 9: 00$ p.m. after at least 3 hours of consuming a low-fat meal, and IR MPH was administrated at $\sim 8: 00$ a.m. after an overnight fast of at least 10 hours. All study drugs were administered with $240 \mathrm{~mL}$ of room temperature water, and water was allowed, as needed, except 1 hour after drug administration. For participants receiving the two HLD200 formulations, a total of 24 serial blood samples were drawn for pharmacokinetic measurements at the following time points over a 48-hour sampling period: predose and $2,3,4,5,6,7,8,9,10,11,12,13,14,15,16,17,18,19,20,24$, 30,36 , and 48 hours after dosing. Safety was monitored throughout the study by assessment of AEs and reviewing the results of physical examinations, vital signs, 12-lead ECGs, and clinical laboratory tests. Since MPH00400 was carried forward for clinical development in children and adolescents with ADHD, only the pharmacokinetics and tolerability of MPH00400 are described further herein. 
Study II. The study on adolescents and children with ADHD was conducted between August and October 2013 in two separate stages, first on adolescents and the second on children, and both stages consisted of two phases, the screening phase and active phase. The screening phase was 14 days long and included an ADHD medication washout period of at least 5 days. On the final day of the washout period and the beginning of the active phase, participants were admitted to the CRU and fitted with an indwelling catheter for repeated plasma sampling and to alleviate the need for multiple needle sticks. Catheters were inserted into a forearm vein by a trained professional, and no more than two attempts were permitted if a forearm vein was difficult to locate. Participants were prohibited from any strenuous or athletic activity 48 hours before admission to the CRU and throughout the entire in-house period of the study. At least 4 hours after ingesting a low-fat dinner, a single 54-mg capsule of HLD200 was administered with $240 \mathrm{~mL}$ of room temperature water in the evening (9:00 p.m. $\pm 30 \mathrm{~min}$ ). Water was allowed, as needed, except for 1 hour after drug administration. Serial blood samples for pharmacokinetic measurements were obtained from all participants just before dosing and over the 48-hour sampling period (18 samples at $0,4,6,8,9,10,11,12,13$, $14,15,16,18,20,22,24,36$, and 48 hours after dosing).

Safety was monitored throughout the study by assessment of AEs and reviewing the results of physical examinations, vital signs, 12-lead ECGs, and clinical laboratory tests. Participants were released from the CRU following their evening blood draw at 24 hours and returned to the CRU the next morning and evening for their remaining 36- and 48-hour blood draws. The final evening visit also served as the end-of-study visit.

\section{Analysis of plasma MPH concentrations}

In both studies, blood samples $(4-6 \mathrm{~mL})$ were collected from indwelling catheters into prechilled sodium fluoride and potassium oxalate vacutainer tubes, placed on ice, and within 30 minutes of collection, centrifuged in a refrigerated centrifuge $\left(4^{\circ} \mathrm{C}\right)$ at $3000 \mathrm{rpm}$ for 10 minutes. Plasma $(\geq 1 \mathrm{~mL})$ was removed and divided into two aliquots, frozen, and batch shipped for analysis. Plasma samples were then analyzed for MPH concentrations by using a standardized and validated high-performance liquid chromatography with tandem mass spectrometry method using MPH-d ${ }_{9}$ as the internal standard (BioPharma Services, Inc., Toronto, ON). Calibration curves were deter- mined for MPH by performing a least-squares (LS) linear regression (weighted $1 / x^{2}$ ) on a set of calibration standards. The calibration curves for MPH were linear in the range from the lower limit of quantitation of $0.1-100 \mathrm{ng} / \mathrm{mL}$ (Study I: $r \geq 0.993$; Study II: $r \geq 0.996$ ). Interassay precision, as measured by the coefficient of variation $(\mathrm{CV})$, for calibration standards ranged from $0.4 \%$ to $2.5 \%$ in Study I and from $0.7 \%$ to $2.4 \%$ in Study II. Interassay precision for quality control samples at concentrations of 3,40,80,500, and $800 \mathrm{ng} / \mathrm{mL}$ ranged from $1.5 \%$ to $3.6 \%$ in Study I and from $1.6 \%$ to $2.7 \%$ in Study II.

\section{Pharmacokinetic analysis}

In both studies, the primary study endpoint was the pharmacokinetic properties (i.e., the rate and extent of absorption of MPH) of a single 54-mg dose of HLD200. Herein, we report on the following pharmacokinetic parameters: maximum concentration $\left(\mathrm{C}_{\max }\right)$, time to maximum concentration $\left(\mathrm{T}_{\max }\right)$, plasma concentration-time area under the curve (AUC) from time zero to the time point with the last quantifiable concentration $\left(\mathrm{AUC}_{0-\mathrm{t}}\right)$, and plasma concentrationtime AUC from time zero to infinity $\left(\mathrm{AUC}_{0-\infty}\right)$. AUCs were calculated by the linear trapezoidal rule. Since these were single-dose studies and participants were not previously dose optimized on HLD200, dose-weight-normalized $\mathrm{C}_{\max }, \mathrm{AUC}_{0-\mathrm{t}}$, and $\mathrm{AUC}_{0-\infty}$ values were calculated by dividing the absolute $\mathrm{C}_{\max }, \mathrm{AUC}_{0-\mathrm{t}}$, and $\mathrm{AUC}_{0-\infty}$, respectively, by the body weight-adjusted dose $(\mathrm{mg} / \mathrm{kg})$ of each participant.

Pharmacokinetic parameters were calculated using noncompartmental analysis (Phoenix WinNonlin, version 6.3, software; Certara, Princeton, NJ). Full precision plasma concentrations and actual sampling times were used for pharmacokinetic and statistical analyses reported in Tables 2 and 3, whereas nominal sampling times were used for the mean plasma concentration-time profiles reported in Figure 1. Additionally, intersubject variability, as measured by the $\mathrm{CV}$ of the time to achieve plasma MPH concentrations of 2, 3, 4, and $5 \mathrm{ng} / \mathrm{mL}$ on the ascending concentration-time curve, was evaluated post hoc in participants who reached these threshold concentrations.

\section{Safety assessments}

In both studies, the secondary endpoint was safety and tolerability, as determined by spontaneously reported or observed AEs,

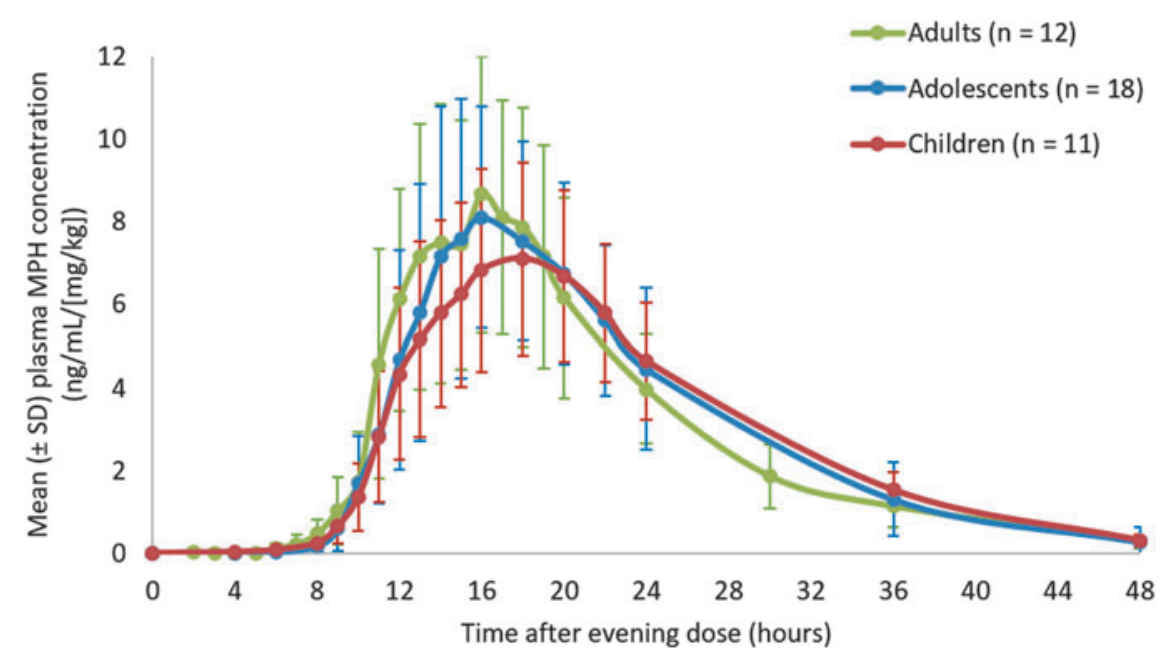

FIG. 1. Dose-weight-normalized mean plasma MPH concentration-time profiles following an evening single-dose administration of HLD200 (54 mg) in healthy adults ( $\geq 18$ years) and in children (6-12 years) and adolescents (13-17 years) with attention-deficit/ hyperactivity disorder. Error bars represent \pm SD of the mean. MPH, methylphenidate; SD, standard deviation. 
Table 1. Demographics and Baseline Characteristics

\begin{tabular}{|c|c|c|c|}
\hline Parameter & Adults $(\mathrm{n}=12)$ & Adolescents $(\mathrm{n}=18)$ & Children $(\mathrm{n}=11)$ \\
\hline \multicolumn{4}{|l|}{ Age (years) } \\
\hline Mean (SD) & $40.4(10.7)$ & $15.4(1.2)$ & $10.5(1.4)$ \\
\hline Median (range) & $45.5(23-54)$ & $15.0(13-17)$ & $11.0(8-12)$ \\
\hline \multicolumn{4}{|l|}{ Gender } \\
\hline Male, $n(\%)$ & $6(50.0)$ & $14(77.8)$ & $6(54.5)$ \\
\hline Female, $n(\%)$ & $6(50.0)$ & $4(22.2)$ & $5(45.5)$ \\
\hline \multicolumn{4}{|l|}{ Height $(\mathrm{cm})$} \\
\hline Mean (SD) & $173.3(13.4)$ & $169.6(6.5)$ & $143.2(6.1)$ \\
\hline Median (range) & $172.9(152.6-194.6)$ & $171.0(155.0-177.5)$ & $145.0(130.0-151.0)$ \\
\hline \multicolumn{4}{|c|}{ Weight at screening $(\mathrm{kg})$} \\
\hline Mean (SD) & $80.9(13.2)$ & $68.7(14.5)$ & $36.1(8.0)$ \\
\hline Median (range) & $78.6(63.6-100.4)$ & $64.4(52.8-103.4)$ & $35.9(25.9-54.0)$ \\
\hline \multicolumn{4}{|l|}{ BMI $\left(\mathrm{kg} / \mathrm{m}^{2}\right)$} \\
\hline Mean (SD) & $26.8(1.3)$ & $23.5(4.5)$ & $17.5(2.8)$ \\
\hline Median (range) & $26.7(24.7-28.7)$ & $22.5(17.2-35.2)$ & $16.6(13.9-23.7)$ \\
\hline
\end{tabular}

BMI, body mass index; SD, standard deviation.

physical examination, suicidality (as measured by the C-SSRS), and absolute values of vital signs (heart rate, respiratory rate, blood pressure, pulse rate, and body temperature), 12-lead ECGs, and clinical laboratory testing (chemistry, hematology, coagulation, urinalysis, and serology). Any values outside the normal range were examined for clinical significance. AEs were coded and summarized using the Medical Dictionary for Regulatory Affairs, version 16, for Study I and version 14 for Study II. For each AE reported, the investigator categorized the $\mathrm{AE}$ by severity, relationship to study medication, and action taken.

\section{Statistical analyses}

Descriptive statistics were used for quantitative parameters. Comparisons of the $90 \%$ confidence intervals (CIs) around the ratios of the LS means of Ln-transformed dose-weight-normalized $\mathrm{C}_{\max }$ and $\mathrm{AUC}_{0-\mathrm{t}}$ were performed. Untransformed median $\mathrm{T}_{\max }$ values were compared using the Mann-Whitney nonparametric test. Statistical analyses of pharmacokinetic parameters were performed using Phoenix WinNonlin, version 6.3, software (Certara). Statistical significance was defined at a $p$-value of $<0.05$.

\section{Results}

\section{Study population}

Participant demographics and baseline characteristics are presented in Table 1. In Study I, a total of 12 healthy adults, ranging from 23 to 54 years of age, were enrolled. In Study II, a total of 30 participants diagnosed with ADHD were enrolled; however, one participant withdrew consent before dosing due to difficulties with catheter insertion. As a result, the total study population included 18 adolescents, ranging from 13 to 17 years of age, and 11 children, ranging from 8 to 12 years of age. In all participants, ADHD pharmacotherapy was discontinued at least 5 days before the beginning of the active phase of the study. Previous pharmacotherapy included lisdexamfetamine dimesylate (Vyvanse $\left.{ }^{\circledR} ; n=10\right)$, dexmethylphenidate hydrochloride IR and ER (Focalin ${ }^{\circledR}$ and Focalin XR ${ }^{\circledR} ; n=5$ and 6 , respectively), osmotic-release oral system MPH (Concerta ${ }^{\circledR}$; $n=5$ ), amphetamine and dextroamphetamine mixed salts (Adderall $\left.\mathrm{XR}^{\circledR}, n=2\right)$, and MPH transdermal system (Daytrana ${ }^{\circledR} ; n=1$ ).

\section{Pharmacokinetics}

Since these were single-dose studies and participants were not previously dose optimized on HLD200, the body weight-adjusted dose varied widely between 0.52 and $2.08 \mathrm{mg} / \mathrm{kg}$, with children receiving higher body weight-adjusted doses (ranges: 0.54$0.85 \mathrm{mg} / \mathrm{kg}$ for adults; $0.52-1.04 \mathrm{mg} / \mathrm{kg}$ for adolescents; and 1.00 $2.08 \mathrm{mg} / \mathrm{kg}$ for children). Tables 2 and 3 provide a summary of the unadjusted and dose-weight-normalized pharmacokinetic data, respectively, for all three populations. As would be expected, mean $\mathrm{C}_{\max }$ and $\mathrm{AUC}_{0-\mathrm{t}}$ values were higher in children and adolescents with ADHD compared with healthy adults due to body weight differences. After correcting for dose and body weight, the doseweight-normalized $\mathrm{C}_{\max }$ appeared to be slightly lower in children with ADHD compared with adolescents with ADHD and healthy

Table 2. Pharmacokinetic Parameters of Methylphenidate Derived Using a Noncompartmental Model Following an Evening Single Dose of HLD200 (54 Mg) in Healthy Adults ( $\geq 18$ Years) and in Adolescents (13-17 Years) and Children (6-12 Years) with Attention-Deficit/Hyperactivity Disorder

\begin{tabular}{|c|c|c|c|}
\hline Pharmacokinetic parameter (unit) & Adults $(\mathrm{n}=12)$ & Adolescents $(\mathrm{n}=18)$ & Children $(\mathrm{n}=11)$ \\
\hline Mean $\mathrm{C}_{\max }(\mathrm{ng} / \mathrm{mL}) \pm \mathrm{CV}(\%)$ & $5.99 \pm 24.0$ & $7.17 \pm 23.7$ & $11.64 \pm 36.3$ \\
\hline Mean $\mathrm{T}_{\max }$ (hours) $\pm \mathrm{CV}(\%)$ & $15.6 \pm 11.1$ & $17.1 \pm 14.5$ & $17.7 \pm 14.1$ \\
\hline Median $\mathrm{T}_{\max }$ (hours) (range) & $16.0(13.0-18.0)$ & $16.2(13.9-22.1)$ & $18.2(12.4-22.0)$ \\
\hline 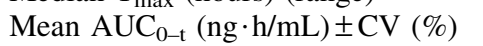 & $83.4 \pm 27.1$ & $105.5 \pm 30.0$ & $205.5 \pm 39.1$ \\
\hline Mean $\mathrm{AUC}_{0-\infty}(\mathrm{ng} \cdot \mathrm{h} / \mathrm{mL}) \pm \mathrm{CV}(\%)$ & Not quantifiable & $109.6 \pm 30.8$ & $210.1 \pm 38.5$ \\
\hline
\end{tabular}

$\mathrm{AUC}_{0-\infty}$, area under the plasma concentration-time curve from zero to infinite time; $\mathrm{AUC}_{0-\mathrm{t}}$, area under the plasma concentration-time curve from zero to the time point with the last quantifiable concentration; $\mathrm{C}_{\max }$, peak plasma concentration; $\mathrm{CV}$, coefficient of variation; $\mathrm{T}_{\max }$, time to peak plasma concentration. 
Table 3. Dose-Weight-Normalized Pharmacokinetic Parameters of Methylphenidate Following an Evening Single Dose of HLD200 (54 mg) in Healthy Adults ( 218 Years) and in Adolescents (13-17 Years) and Children (6-12 Years) with AtTention-Deficit/Hyperactivity Disorder

\begin{tabular}{lcrr}
\hline Dose-weight-normalized pharmacokinetic parameter $($ unit) & Adults $(\mathrm{n}=12)$ & Adolescents $(\mathrm{n}=18)$ & Children $(\mathrm{n}=11)$ \\
\hline Mean $\mathrm{C}_{\max }([\mathrm{ng} / \mathrm{mL}] /[\mathrm{mg} / \mathrm{kg}]) \pm \mathrm{CV}(\%)$ & $9.13 \pm 35.2$ & $8.84 \pm 34.5$ & $7.44 \pm 30.1$ \\
Mean $\mathrm{ACC}_{0-\mathrm{t}}([\mathrm{ng} \cdot \mathrm{h} / \mathrm{mL}] /[\mathrm{mg} / \mathrm{kg}]) \pm \mathrm{CV}(\%)$ & $126.5 \pm 35.5$ & $129.4 \pm 34.8$ & $129.7 \pm 27.3$ \\
Mean $\mathrm{AUC}_{0-\infty}([\mathrm{ng} \cdot \mathrm{h} / \mathrm{mL}] /[\mathrm{mg} / \mathrm{kg}]) \pm \mathrm{CV}(\%)$ & Not quantifiable & $134.4 \pm 35.7$ & $132.7 \pm 27.2$ \\
\hline
\end{tabular}

$\mathrm{AUC}_{0-\infty}$, area under the plasma concentration-time curve from zero to infinite time; $\mathrm{AUC}_{0-t}$, area under the plasma concentration-time curve from zero to the time point with the last quantifiable concentration; $\mathrm{C}_{\mathrm{max}}$, peak plasma concentration; $\mathrm{CV}$, coefficient of variation.

adults. This is a result of the higher body weight-adjusted doses in children with ADHD. Nonetheless, comparisons of the LS mean ratios for the Ln-transformed values revealed that the dose-weightnormalized $\mathrm{C}_{\max }$ of children with ADHD did not differ significantly from those of the other two age groups (Table 4). Furthermore, the dose-weight-normalized $\mathrm{AUC}_{0-\mathrm{t}}$ values were similar among all age groups, which was also confirmed by the $90 \%$ CIs of the LS mean ratios for the Ln-transformed values (Table 4). Early drug exposure from 0 to 10 hours after evening dosing (9:00 p.m. to 7:00 a.m.) was, on average, $<3 \%$ of total drug exposure in healthy adults (mean $\mathrm{AUC}_{0-10} \pm$ standard deviation $[\mathrm{SD}]: 1.8 \pm 1.3 \mathrm{ng} \cdot \mathrm{h} / \mathrm{mL}$ ) and in adolescents and children with $\mathrm{ADHD}$ (mean $\mathrm{AUC}_{0-10} \pm \mathrm{SD}$ : $1.1 \pm 0.73 \mathrm{n} \cdot \mathrm{h} / \mathrm{mL}$ and $2.7 \pm 1.6$, respectively), indicating that there is an approximate 10-hour delay in initial drug release. The median time to achieve peak concentration was $\sim 2$ hours later in children compared with adolescents and adults (18.2 vs. 16.2 and 16.0 hours, respectively); however, a statistical difference was only found between adults and children with ADHD $(p=0.003)$ (Table 4).

Table 4. Comparisons of Pharmacokinetic Parameters of Methylphenidate Following an Evening Single

Dose of HLD200 (54 Mg) IN Healthy Adults ( $\geq 18$ Years) AND IN AdOLESCENTS (13-17 YeARS) AND CHILDREN (6-12 Years) With Attention-Deficit/ HYPERACTIVITY DISORDER

\begin{tabular}{|c|c|c|c|}
\hline Parameter & $\begin{array}{l}\text { Ratio } \\
\text { of LS } \\
\text { mean }\end{array}$ & $\begin{array}{l}90 \% \\
\text { CI of } \\
\text { ratio }\end{array}$ & $\mathrm{p}$-Value \\
\hline \multicolumn{4}{|l|}{ Adults versus Adolescents } \\
\hline $\begin{array}{l}\text { GM LS mean } \mathrm{C}_{\max }{ }^{\mathrm{a}} \\
([\mathrm{ng} / \mathrm{mL}] /[\mathrm{mg} / \mathrm{kg}])\end{array}$ & 1.03 & $(0.84,1.25)$ & 0.83 \\
\hline $\begin{array}{l}\text { GM LS mean AUC } \mathrm{AU}_{0-\mathrm{t}} \\
\quad([\mathrm{ng} \cdot \mathrm{h} / \mathrm{mL}] /[\mathrm{mg} / \mathrm{kg}])\end{array}$ & 0.96 & $(0.78,1.20)$ & 0.82 \\
\hline Median $\mathrm{T}_{\max }$ (hours) & - & - & 0.15 \\
\hline \multicolumn{4}{|l|}{ Adults versus Children } \\
\hline $\begin{array}{l}\text { GM LS mean } C_{\max } \\
([\mathrm{ng} / \mathrm{mL}] /[\mathrm{mg} / \mathrm{kg}])\end{array}$ & 1.21 & $(0.96,1.51)$ & 0.17 \\
\hline $\begin{array}{l}\text { GM LS mean AUC } \mathrm{AU}_{0-\mathrm{t}} \\
\quad([\mathrm{ng} \cdot \mathrm{h} / \mathrm{mL}] /[\mathrm{mg} / \mathrm{kg}])\end{array}$ & 0.95 & $(0.75,1.20)$ & 0.71 \\
\hline Median $\mathrm{T}_{\max }$ (hours) & - & - & 0.003 \\
\hline \multicolumn{4}{|l|}{ Adolescents versus Children } \\
\hline $\begin{array}{l}\text { GM LS mean } \mathrm{C}_{\max } \\
([\mathrm{ng} / \mathrm{mL}] /[\mathrm{mg} / \mathrm{kg}])\end{array}$ & 1.18 & $(0.96,1.45)$ & 0.19 \\
\hline $\begin{array}{l}\text { GM LS mean AUC } \\
\quad([\mathrm{ng} \cdot \mathrm{h} / \mathrm{mL}] /[\mathrm{mg} / \mathrm{kg}])\end{array}$ & 0.98 & $(0.79,1.22)$ & 0.85 \\
\hline Median $\mathrm{T}_{\max }$ (hours) & - & - & 0.29 \\
\hline
\end{tabular}

${ }^{\mathrm{a}}$ Within the CI limits of $0.8-1.25$.

$\mathrm{AUC}_{0-\mathrm{t}}$, area under the plasma concentration-time curve from zero to the time point with the last quantifiable concentration; CI, confidence interval; $\mathrm{C}_{\max }$, peak plasma concentration; GM, geometric mean; LS, least squares; $\mathrm{T}_{\max }$, time to peak plasma concentration.
This statistical difference in median $\mathrm{T}_{\max }$ between children with ADHD and healthy adults is not considered to be clinically meaningful. Similarly, the mean time to achieve peak concentration was comparable for both children and adolescents with ADHD (mean $\mathrm{T}_{\max }$ : 17.7 and 17.1 hours, respectively), with both groups demonstrating low intersubject variability (CV: $14.1 \%$ and $14.5 \%$, respectively), and occurred about 2 hours later than in healthy adults (mean $\mathrm{T}_{\max }$ : 15.6 hours; $\mathrm{CV}: 11.1 \%$ ).

The dose-weight-normalized mean plasma MPH concentrationtime profiles for healthy adults and for adolescents and children with ADHD following an evening administration of a single 54-mg capsule of HLD200 are shown in Figure 1. Visual inspection of these pharmacokinetic profiles revealed that the absorption profile was similar among the three populations. The pharmacokinetic profiles of healthy adults and children and adolescents with ADHD were nearly superimposable, with low interpatient variability over the 48-hour testing period. After a delay in the initial drug release of $\sim 8$ hours, plasma MPH concentrations increased rapidly and peaked at 16-18 hours after dosing. This was followed by a slower decline in drug concentrations, demonstrating extended drug release characteristics. In addition, more than $50 \%$ of drug exposure appears to occur after peak concentrations are reached, suggesting that HLD200 has a prolonged absorption phase. MPH was eliminated from the system 48 hours after initial administration. Interestingly, intersubject variability in the time to achieve a specific plasma MPH concentration $(2-5 \mathrm{ng} / \mathrm{mL})$ on the ascending concentration-time curve following a single-dose administration was also low in both children (CV: $7.8 \%-12.1 \%)$ and adolescents (CV: 9.0\%-12.8\%) with ADHD and healthy adults (CV: 11.3\%-17.7\%) (Table 5). At a dose of $54 \mathrm{mg}$ of HLD200, some healthy adults did not reach the threshold plasma concentrations of 4 and $5 \mathrm{ng} / \mathrm{mL}$, and this may have contributed to a slightly higher intersubject variability.

\section{Safety analysis}

In healthy adults, four AEs were reported with the slow-release formulation of HLD200 (MPH00400), and all AEs were either mild $(n=3)$ or moderate $(n=1)$ in severity. Two of the AEs were determined by the investigator to be possibly $(n=1)$ or probably $(n=1)$ related to study drug treatment and the other two as unlikely related to study drug treatment. All AEs resolved and only one AE required treatment with concomitant medications. None of the AEs were serious or required a change in study medication. The specific AEs reported for participants receiving the slow-release formulation of HLD200 (MPH00400) were constipation $(n=1)$, anxiety $(n=2)$, and dysmenorrhea $(n=1)$.

In adolescents and children with $\mathrm{ADHD}, 16$ participants experienced AEs, with seven AEs experienced by 6 children (54.5\%) and 10 AEs experienced by 10 adolescents (55.6\%). In children, all AEs were mild and not related to study drug treatment. In adolescents, 
Table 5. Following Single-Dose Administration of HLd200 (54 mg), Intersubject Variability, As Measured

by the Coefficient in Variation, in the Mean Time to Achieve an Ascending Plasma Methylphenidate

Concentration Ranging from 2 to 5 NG/mL in Healthy Adults ( $\geq 18$ Years) and in Adolescents (13-17 Years) and Children (6-12 Years) with Attention-Deficit/Hyperactivity Disorder

\begin{tabular}{|c|c|c|c|c|c|c|}
\hline \multirow[b]{2}{*}{$\begin{array}{l}\text { Plasma MPH } \\
\text { concentration } \\
(\text { ng/mL) }\end{array}$} & \multicolumn{2}{|l|}{ Adults } & \multicolumn{2}{|l|}{ Adolescents } & \multicolumn{2}{|l|}{ Children } \\
\hline & $\begin{array}{c}\text { Mean time to achieve } \\
\text { ascending plasma MPH } \\
\text { concentration (hours) } \pm C V(\%)\end{array}$ & $\mathrm{n}$ & $\begin{array}{c}\text { Mean time to achieve } \\
\text { ascending plasma MPH } \\
\text { concentration (hours) } \pm C V(\%)\end{array}$ & $\mathrm{n}$ & $\begin{array}{c}\text { Mean time to achieve } \\
\text { ascending plasma MPH } \\
\text { concentration (hours) } \pm C V(\%)\end{array}$ & $\mathrm{n}$ \\
\hline 2 & $10.8 \pm 11.3$ & 12 & $11.2 \pm 9.04$ & 18 & $10.3 \pm 7.80$ & 11 \\
\hline 3 & $11.6 \pm 13.7$ & 12 & $12.0 \pm 9.30$ & 18 & $11.0 \pm 9.90$ & 11 \\
\hline 4 & $12.2 \pm 13.8$ & $11^{\mathrm{a}}$ & $12.9 \pm 10.8$ & 18 & $11.6 \pm 11.4$ & 11 \\
\hline 5 & $13.6 \pm 17.7$ & $9^{a}$ & $13.8 \pm 12.8$ & $16^{\mathrm{a}}$ & $12.1 \pm 12.1$ & 11 \\
\hline
\end{tabular}

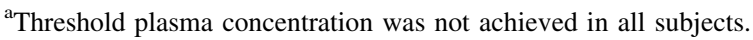

$\mathrm{CV}$, coefficient of variation; MPH, methylphenidate.

AEs were either mild $(n=9)$ or moderate $(n=1)$ in severity, and five AEs were determined by the investigator to be possibly $(n=3)$ or probably $(n=2)$ related to study drug treatment. In both populations, no serious or severe AEs were reported in the study, and none of the study participants experienced an AE leading to death or discontinuation from the study. The most frequently reported AEs $(\geq 10 \%)$ were upper abdominal pain $(n=2)$ and upper respiratory infection $(n=2)$ in adolescents and pharyngitis $(n=2)$ and dizziness $(n=2)$ in children. No sleep-related AEs were reported in either group. There were no clinically meaningful differences in vital signs and ECG evaluations at any time point over the entire duration of the study.

\section{Discussion}

Although currently available ER formulations of MPH provide an extended duration of effect of up to 12 hours after dosing, the onset of efficacy can be protracted by up to 2 hours, leaving a significant portion of the early morning period without adequate control of ADHD symptoms (Childress 2016; Childress and Tran 2016). Accordingly, there is a significant unmet need for treatments that provide clinically meaningful control of early morning ADHD symptoms and EMF impairment (Sallee 2015). HLD200 is the only DR/ER-MPH formulation designed to be taken at night to achieve early morning control of ADHD symptoms and reduce EMF impairment upon awakening, as well as provide persistent and continued coverage throughout the day. The main findings of these open-label, single-center, single-dose pharmacokinetic studies were that evening-dosed HLD200 (1) produces a consistent and predictable delay in the initial release of MPH, followed by a period of extended controlled release and (2) results in similar pharmacokinetic profiles in healthy adults and in adolescents and children with ADHD after accounting for differences in body weights.

Unlike currently available long-acting MPH formulations, which are administered in the morning, HLD200 is uniquely designed to be taken at night with the intent of releasing MPH just before awakening (Childress 2016). Indeed, the 8- to 10-hour delay in MPH release observed in the present study coincides with the preawakening period, suggesting that there was no premature release of MPH from the formulation during the sleep cycle and that the DR properties of HLD200 are functioning as intended. To provide a consistent delay in the initial release of MPH, the physicochemical properties of HLD200 were specifically engineered to take advantage of several aspects of GI physiology. Specifically, the outer DR layer was formulated to comprise a combination of hydrophobic, hygroscopic, and $\mathrm{pH}$-dependent properties with the intent of targeting ileocolonic drug delivery and ensuring that the delay in the onset of drug delivery was not solely reliant on either GI transit time or $\mathrm{pH}$. The rationale was that after ingestion, the hydrophobic and insoluble polymers would initially resist wetting as the HLD200 microbeads transit the upper GI tract, thereby delaying dissolution. Over time, the hydrophobic and hygroscopic polymers in the DR layer would slowly start to wet, allowing GI fluids to gain access to a $\mathrm{pH}$-sensitive polymer widely used to target drug delivery to the colon. When the DR layer is fully wet, it would not begin to erode until it was exposed to a $\mathrm{pH}$ of 7 or greater, the $\mathrm{pH}$ at which the $\mathrm{pH}$-sensitive polymer becomes soluble (Watts and Illum 1997; Ibekwe et al. 2006).

Once the DR layer begins to erode, it ultimately begins to expose the inner ER layer, which was formulated to consist of hydrophobic and soluble polymers that regulate permeability and tightly control dissolution of the active ingredient from the drug-loaded core containing MPH. These properties are thought to control the rate at which GI fluids gain accessibility to the drug-loaded core and the rate at which the drug diffuses out of the core. As observed in this study, after the 8- to 10-hour delay in drug release, plasma MPH concentrations increased rapidly, producing a smooth ascending MPH absorption profile. This ascending profile is thought to minimize or prevent the development of acute tolerance (Swanson et al. 1999, 2003). Once peak MPH concentrations were achieved at $\sim 16-18$ hours, there was a slower decline in drug concentrations, demonstrating the extended drug release properties of HLD200. Indeed, in the present study, it was observed that more than half of MPH exposure occurs after $\mathrm{T}_{\max }$, which corresponds with the early afternoon. Relative to existing MPH formulations (Maldonado 2013; Childress 2016), HLD200 exhibits a protracted elimination phase that is likely due its targeted drug delivery to the relatively less absorptive colon. This suggests that the elimination phase of HLD200 does not consist of pure elimination, but rather the sum of continued slow absorption in the colon and elimination. Furthermore, the resulting prolonged absorption window suggests that HLD200 may have an extended duration of effect; however, this needs to be confirmed in future well-controlled studies.

Based on the hydrophobic, hydrophilic, and pH-dependent properties of the DR and ER layers, the initial dissolution of HLD200 and subsequent absorption of MPH are not dependent on any single factor (e.g., pH, GI transit, or site of release). A recent literature review of GI physiologic characteristics was conducted by the FDA to provide a knowledge base for assessing the potential effects of age on the in vivo performance of orally absorbed, systematically active drug products (Bai et al. 2016). It was concluded that even though total GI transit times are similar for children (8-14 years) and adults (18-65 
years), total GI transit times of small solids are much shorter for children than in adults. Furthermore, gastric, duodenal, jejunal, and colonic $\mathrm{pH}$ levels are similar for children and adults; however, children tend to have a slightly lower cecal $\mathrm{pH}$. While it is unknown if there were any differences in the GI physiology of the participants in the present study, there were no significant differences in the pharmacokinetic findings between healthy adults and children and adolescents with ADHD, and the dose-weight-adjusted pharmacokinetic profiles were similar across all three populations. Accordingly, it is not expected that slight differences in GI physiology would affect the pharmacokinetics of HLD200.

Following a single-dose administration, intersubject variability, as measured by the $\mathrm{CV}$, was low for the mean time to achieve an ascending plasma MPH concentration at concentrations ranging from 2 to $5 \mathrm{ng} / \mathrm{mL}$ in both children and adolescents with ADHD $(\mathrm{CV}<13 \%)$ and in healthy adults (CV: 11.3\%-17.7\%). Similarly, low intersubject variability was observed in mean $\mathrm{T}_{\max }$ in all populations $(\mathrm{CV}$ $<14.5 \%$ ). This level of precision is unprecedented in the delivery of MPH with oral dosing. The clinical implications of these findings suggest that the precision of MPH release could be highly predictable.

Given the low intersubject variability and the monophasic pharmacokinetic profile with no peak-to-trough fluctuations during a singledose administration, HLD200 would be expected to be well tolerated. Overall, evening administration of a single dose of HLD200 was in fact well tolerated in both studies. No serious or sleep-related AEs were reported in healthy adults or in children and adolescents with ADHD. AEs that did occur were mild to moderate, limited in nature, and predictable from the known side effect profile of MPH (Childress 2016). Moreover, no significant safety issues emerged following treatment.

The results of these pharmacokinetic studies need to be considered in light of their potential limitations. First, while the sample sizes of both studies are small, they are characteristic of trials investigating pharmacokinetic parameters. Second, since HLD200 was administered under strict study conditions, the variability and tolerability may or may not differ in a naturalistic setting. Third, all children and adolescents with ADHD were required to be stimulant responders to ensure that they would reasonably be able to tolerate the study medication. This is standard practice in pharmacokinetic trials of children and adolescents with ADHD, where safety measures are secondary or exploratory in nature and require further investigation in phase 3 trials that are more appropriately designed for evaluating safety and tolerability. As such, as with any other pharmacokinetic study, it is important that caution is exercised in the interpretation of AEs reported herein. For example, while no sleeprelated AEs were reported or observed in these studies, it is important to note that the interpretation of these findings may be limited as this was a single-dose study and some participants were awakened for blood sampling during the night. The safety and efficacy of HLD200 in children with ADHD have been evaluated in three phase 3 trials (NCT02255513, NCT02493777, and NCT02520388), and the detailed findings of these trials will better inform and address the limitations described above.

Numerous formulation strategies have been utilized in developing long-acting MPH preparations, including an osmotic controlledrelease oral delivery system, various combinations of IR and ER beads, multilayered beads with IR and ER layers, a transdermal patch, and liquid suspensions (López and Leroux 2013; Childress 2016). Consequently, despite having comparable levels of total drug exposure, their pharmacokinetic profiles differ in the time it takes to achieve peak plasma MPH concentrations, rate at which the peak levels are reached and decline, and levels of early and late exposure (Maldonado 2013). This is attributed to differences in their formu- lations and the ratio of IR to ER MPH within each formulation, which deliver varying proportions of MPH at different periods of the day (Maldonado 2013). That is, formulations containing higher amounts of IR MPH display more rapid absorption and higher plasma MPH concentrations in the initial hours after administration, whereas those with higher amounts of ER MPH have a more protracted absorption window with higher plasma MPH concentrations occurring later in the day (Maldonado 2013). As would be expected, larger improvements in efficacy were evident in the morning with formulations that have higher plasma MPH concentrations in the initial hours after dosing, whereas those with higher plasma MPH concentrations occurring later in the day have better efficacy in the afternoon and evening (Maldonado 2013). In other words, with existing stimulants, efficacy earlier in the day may come at the expense of efficacy later in the day, and vice versa, and this is, in part, influenced by the pharmacokinetic profile. Based solely on the pharmacokinetic profile of HLD200 and the assumption that greater efficacy will occur during the absorption phase, it would be expected that HLD200 would provide coverage upon awakening and throughout the day; however, this needs to be elucidated in clinical trials (Swanson et al. 1999, 2003).

\section{Conclusions}

HLD200, a new DR/ER-MPH formulation, achieved the intended pharmacokinetic profile in healthy adults and in children and adolescents with ADHD. Specifically, there was an approximate 8- to 10-hour delay in the release of MPH, after which plasma MPH concentrations increased rapidly, achieving a smooth ascending plasma concentration profile and reaching $\mathrm{T}_{\max }$ at $\sim 16$ 18 hours after dosing. This was followed by a slower decline in drug concentrations, demonstrating the extended drug-release properties of HLD200 and thereby its long absorption window. As would be expected, when body weight was taken into account, there were no significant differences in the pharmacokinetic findings between healthy adults and children and adolescents with ADHD, and their dose-weight-adjusted pharmacokinetic profiles appeared to be monophasic and nearly superimposable.

\section{Clinical Significance}

Although multiple long-acting stimulants are available, there remains a significant unmet need in children 6-17 years of age to provide clinically meaningful control of EMF impairment from inadequately controlled ADHD symptoms (Sallee 2015). The most commonly prescribed long-acting stimulant formulations can leave up to 2 hours of the early morning routine without adequate control of ADHD symptoms and related functional impairment (Sallee 2015; Childress 2016; Childress and Tran 2016). HLD200 is the only DR/ ER-MPH formulation designed to be taken at night to provide clinically meaningful control of ADHD symptoms and impaired functioning upon awakening, throughout the day, and lasting into the evening. The consistent 8- to 10-hour delay in the initial release of MPH following evening administration of HLD200 is coincident with the early morning preawakening period. This suggests that there is a lower likelihood of drug-induced insomnia due to the formulation. The smooth ascending absorption profile occurring the following morning and the slower decline in drug concentration after peak concentrations are achieved, suggesting that HLD200 has the potential to control ADHD symptoms and impaired functioning from the early morning and lasting into the evening. To determine safety and tolerability in addition to whether HLD200 is effective in reducing inadequately controlled ADHD symptoms and early morning 
and late afternoon/evening functional impairments, three clinical trials in children with ADHD have been recently conducted and the findings will be published in the foreseeable future (NCT02255513, NCT02493777, and NCT02520388). Study registry identification number: NCT01907360.

\section{Acknowledgments}

The authors would like to thank the parents and their children who participated in the study. All authors analyzed and interpreted the study data, contributed to the content of the manuscript, critically reviewed the drafts, and approved the final version for submission. Under the direction of the authors, Marina Komolova, $\mathrm{PhD}$, provided medical writing assistance for the manuscript, funding for which was provided by Ironshore Pharmaceuticals and Development, Inc.

\section{Disclosures}

Dr. A.C. has served on advisory boards for Neurovance, Shionogi, Pfizer, Arbor, Rhodes, Shire, Neos, Akili and Tris. She is a consultant for Arbor, Ironshore Pharmaceuticals and Development, Inc., Neos, NextWave Pharmaceuticals, NLS Pharma, Novartis Pharmaceutical Corporation, Pfizer, Rhodes, Tris, Purdue, Sunovion, and Shire. Dr. A.C. has received research support from Alcobra, Arbor, Forest Research Institute, Ironshore, Johnson and Johnson Pharmaceutical Research and Development, LLC, Lilly USA, LLC, Lundbeck, Neos, Neurovance, NextWave Pharmaceuticals, Novartis Pharmaceutical Corporation, Noven, Otsuka, Pfizer, Purdue, Rhodes, Shionogi, Shire, Somerset Pharmaceuticals, Inc., Sunovion, Theravance, Tris, Medgenics, Akili, and Pearson. Dr. A.C. also received grant support from the Food and Drug Administration (FDA). She is a speaker for Novartis Pharmaceutical Corporation, Pfizer, Shionogi, Shire, Tris, Neos, and Arbor. Ms. S.M. has nothing to disclose. Dr. J.G. (University of Maryland) received research support from the FDA and Eli Lilly, Aeolus, and Wockhardt. Dr. B.I. is an employee of Ironshore Pharmaceuticals and Development, Inc., and Mr. N.J.D. and Dr. A.M. are consultants to Ironshore Pharmaceuticals and Development, Inc.

\section{References}

Bai JP, Burckart GJ, Mulberg AE: Literature review of gastrointestinal physiology in the elderly, in pediatric patients, and in patients with gastrointestinal diseases. J Pharm Sci 105:476-483, 2016.

Birmaher B, Greenhill LL, Cooper TB, Fried J, Maminski B. Sustained release methylphenidate: Pharmacokinetic studies in ADDH males. J Am Acad Child Adolesc Psychiatry 28:768-772, 1989.

Childress A, Tran C: Current investigational drugs for the treatment of attention-deficit/hyperactivity disorder. Expert Opin Investig Drugs 25:463-474, 2016.

Childress AC: Methylphenidate HCL for the treatment of ADHD in children and adolescents. Expert Opin Pharmacother 17:1171-1178, 2016.

Faraone SV, Schachar RJ, Barkley RA, Nullmeier R, Sallee FR: Early morning functional impairments in stimulant-treated children with attention-deficit/hyperactivity disorder versus controls: Impact on the family. J Child Adolesc Psychopharmacol [Epub ahead of print]; DOI: 10.1089/cap.2016.0164, 2017

Hubbard JW, Srinivas NR, Quinn D, Midha KK. Enantioselective aspects of the disposition of dl-threo-methylphenidate after the administration of a sustained-release formulation to children with attention deficit-hyperactivity disorder. J Pharm Sci 78:944-947, 1989.
Ibekwe VC, Liu F, Fadda HM, Khela MK, Evans DF, Parsons GE, Basit AW: An investigation into the in vivo performance variability of $\mathrm{pH}$ responsive polymers for ileo-colonic drug delivery using gamma scintigraphy in humans. J Pharm Sci 95:2760-2766, 2006.

López FA, Leroux JR: Long-acting stimulants for treatment of attentiondeficit/hyperactivity disorder: A focus on extended-release formulations and the prodrug lisdexamfetamine dimesylate to address continuing clinical challenges. Atten Defic Hyperact Disord 5:249265, 2013.

Maldonado R: Comparison of the pharmacokinetics and clinical efficacy of new extended-release formulations of methylphenidate. Expert Opin Drug Metab Toxicol 9:1001-1014, 2013.

McGough JJ, Barkley RA: Diagnostic controversies in adult attention deficit hyperactivity disorder. Am J Psychiatry 161:1948-1956, 2004.

Pelham WE, Jr., Sturges J, Hoza J, Schmidt C, Bijlsma JJ, Milich R, Moorer S: Sustained release and standard methylphenidate effects on cognitive and social behavior in children with attention deficit disorder. Pediatrics 80:491-501, 1987.

Pliszka S, AACAP Work Group on Quality Issues: Practice parameter for the assessment and treatment of children and adolescents with attention-deficit/hyperactivity disorder. J Am Acad Child Adolesc Psychiatry 46:894-921, 2007.

Sallee FR: Early morning functioning in stimulant-treated children and adolescents with attention-deficit/hyperactivity disorder and its impact on caregivers. J Child Adolesc Psychopharmacol 25:558-565, 2015.

Subcommittee on Attention-Deficit/Hyperactivity Disorder and Steering, Committee on Quality Improvement and Management, Wolraich M, Brown L, Brown RT, DuPaul G, Earls M, Feldman HM, Ganiats TG, Kaplanek B, Meyer B, Perrin J, Pierce K, Reiff M, Stein MT, Visser S: ADHD: Clinical practice guideline for the diagnosis, evaluation, and treatment of attention-deficit/hyperactivity disorder in children and adolescents. Pediatrics 128:1007-1022, 2011.

Swanson J, Gupta S, Guinta D, Flynn D, Agler D, Lerner M, Williams L, Shoulson I, Wigal S: Acute tolerance to methylphenidate in the treatment of attention deficit hyperactivity disorder in children. Clin Pharmacol Ther 66:295-305, 1999.

Swanson J, Gupta S, Lam A, Shoulson I, Lerner M, Modi N, Lindemulder E, Wigal S: Development of a new once-a-day formulation of methylphenidate for the treatment of attention-deficit/hyperactivity disorder: Proof-of-concept and proof-of-product studies. Arch Gen Psychiatry 60:204-211, 2003.

Volkow ND, Fowler JS, Wang G, Ding Y, Gatley SJ: Mechanism of action of methylphenidate: Insights from PET imaging studies. J Atten Disord 6 Suppl 1:S31-S43, 2002.

Watts PJ, Illum L: Colonic drug delivery. Drug Dev Ind Pharm 23:893913, 1997.

Whalen CK, Henker B, Jamner LD, Ishikawa SS, Floro JN, Swindle R, Perwien AR, Johnston JA: Toward mapping daily challenges of living with ADHD: Maternal and child perspectives using electronic diaries. J Abnorm Child Psychol 34:115-130, 2006.

Wilens TE, Spencer TJ: Understanding attention-deficit/hyperactivity disorder from childhood to adulthood. Postgrad Med 122:97-109, 2010.

Willcutt EG: The prevalence of DSM-IV attention-deficit/hyperactivity disorder: A meta-analytic review. Neurotherapeutics 9:490-499, 2012.

Address correspondence to: Ann Childress, $M D$ Center for Psychiatry and Behavioral Medicine 7351 Prairie Falcon Rd, Suite 160 Las Vegas, NV 89128

E-mail: drann87@aol.com 